\title{
On Application of Modern Technology in Professional Training to Improve Staff Efficiency
}

\author{
Bannikov S.A. \\ State Air Traffic Management Corporation of the Russian \\ Federation, \\ Moscow, Russia, \\ sabann@bk.ru
}

\author{
Kornienko A.A. \\ Financial University under the Government of the Russian \\ Federation, \\ Moscow, Russia, \\ A1n9n9a8@mail.ru
}

\begin{abstract}
In the context of the global informatization and computerization of production and economic processes, the activity of an enterprise is impossible without involving people. People are a component of the enterprise's resources that are necessary to fulfill its goals and objectives: they become "labor" or "human" resources. To improve the efficiency of the personnel management system at the enterprise, it is necessary to search for new tools and methods for constructing, functioning and developing a special separate element of the management system responsible for working with personnel. In the process of developing and implementing various management decisions that can ensure an increase in the efficiency and effectiveness of activities, an important role belongs to the construction, analysis, assessment and development of the personnel management system of enterprises. It is also very important to identify the structural elements of this system, evaluate their performance and work out ways of development. Significant importance in this process is given to the construction and assessment of the personnel management unit, since it is one of the most important elements of the enterprise personnel management system. Carrying out a high-quality and effective construction and assessment of the activities of the personnel management unit requires the formation of an objective, reliable and complete database of the personnel management system, the state of staffing and personnel administration for the development and adoption of appropriate management decisions. Despite a significant amount of theoretical and applied research, a number of important scientific problems remain unresolved. In particular, it is necessary to develop a typology of types of personnel management units (PMU) and systematize the factors of their influence. The methodology for assessing indicators for constructing and evaluating the activities of the personnel management unit requires a fundamental improvement; it is also necessary to determine the model for building and developing the personnel management unit. It is important to design organizational structures of personnel management units for enterprises, which makes it possible to single out the structural subsystems of the personnel management unit, to highlight the most important subsystems for each enterprise, to establish economic indicators for assessing and building a personnel management unit, as well as to study the state of personnel management in order to determine the possibility of transformation of a personnel management unit into a separate element of the management system.
\end{abstract} economy

Keywords—staff, management, enterprise, development,

\section{INTRODUCTION}

The effective performance of the personnel management unit is expressed both in the performance of the unit itself and in the performance of the whole enterprise, since the main task of the PMU is to ensure the organized work of all personnel of the enterprise [1]. The PMU will be optimal and efficient if the enterprise achieves both the goals in the field of work with personnel and the goals of the enterprise itself [2]. Accordingly, it becomes necessary to assess the work of the personnel management unit, which ensures the achievement of the above-mentioned goals [3].

Our studies led us to the conclusion that enterprises predominantly assess the efficiency of personnel, but practically no assessment of the activities of the unit that coordinates work with personnel is carried out [4]. In the works of Russian scientists, the assessment of efficiency is mainly considered from the standpoint of researching personnel costs and determining whether they are effective in the context of the profit received. A significant emphasis is placed on the efficiency of using labor potential. Thus, the productivity, time of work, labor intensity of work and its quality are studied.[5] According to the state methods of personnel assessment, observations are made on staff turnover, employment level, professional distribution, age structure, and gender distribution [6]. However, all these indicators cannot reflect the practical state of personnel management in enterprises [7]. Accordingly, this led to the need to develop tools for assessing personnel management through the prism of assessing the activities of the unit that implements functions in the field of personnel management [8].

For this purpose, based on the identified typical structure of the personnel management unit, which includes 12 subsystems, we propose to conduct an assessment based on the following three types of PMU performance [9]:

- economic;

- organizational; 
- social.

\section{RESEARCH MATERIALS}

From the standpoint of economic efficiency, it is necessary to evaluate the overall performance of the enterprise together with the personnel management unit [10].

The organizational effectiveness of the management unit will be determined from the standpoint of the rationality of its construction, the performance of certain functions and the development of workers [11]. As for social efficiency, it is advisable to consider the role of the personnel management unit in the social development of employees, the enterprise and the social component of the enterprise in the external environment [12]. On the basis of these efficiencies, we propose to calculate indicators that will make it possible to find out the current level of activity of the personnel management unit in three vectors and to determine the integral indicator of performance [13].

\section{FINDINGS}

One of the problematic aspects of distinguishing of a personnel management unit in the structure of an enterprise's activities is the unreasoned conclusions of managers that such units are not directly involved in making a profit [14]. Therefore, one of the criterion for justifying the feasibility of distinguishing the PMU is to use the indicator of the economic feasibility of the functioning of the PMU (EDoup), which we will calculate as [15]:

$$
\text { EDoup=Voup/Vz }
$$

Voup is the cost of operating the PMU, Vz is the total cost.

If the expense ratio is growing and the main financial result at the same time shows a tendency to decrease, then the management needs to revise personnel work, in particular, possible ways to reduce costs and the work of the personnel management unit in terms of the main resulting indicators.

The economic efficiency of PMU activities will be expressed through the effect of expenditures incurred on PMU activities, that is, the ratio of net to the above-mentioned costs [16]. Accordingly, the economic efficiency of the PMU will be calculated:

\section{Eeoup=CHP/Voup}

The normative value of this indicator is its growth in dynamics. To assess the economic efficiency, we propose to use only the so-called profitability indicator of the functioning of the PMU (Eeoup), since at the overwhelming majority of enterprises the management considers this approach appropriate.

In the case of the functioning of a personnel management unit at an enterprise, economic efficiency can be enhanced by calculating organizational efficiency, because it will allow to find out which subsystems of the personnel management unit can influence the performance of personnel, which in the future directly affects the financial result obtained [17].

We propose to calculate the organizational effectiveness of the personnel management unit on the basis of two aspects [18]:

- semantic;

- structural.

The semantic direction is expressed in the assessment of the PMU from the point of view of semantic purpose, so it should take into account the fulfillment of all tasks of the PMU, its promptness, professionalism and performance. [19]. Accordingly, substantive criteria will be:

- the level of fulfillment of tasks by the personnel management unit;

- indicator of efficiency in the fulfillment of PMU tasks;

- the level of professionalism of the PMU.

Let's consider each of them.

The level of fulfillment of tasks by the personnel management unit expresses the meaningful activity of the latter, the rationality of its construction. If the tasks assigned to the PMU are fully fulfilled, this means that its structure is rational. The level of fulfillment of tasks by the personnel management unit (RRZ) will be calculated as follows:

$$
\text { Rrz=Zv/Zoup }
$$

where $\mathrm{Zv}$ is the number of tasks planned for the estimated period and fully completed by the personnel management unit; Zoup is the total number of tasks scheduled to be performed by the unit for the estimated period.

The criterion of efficiency is $100 \%$ fulfillment of the assigned tasks with a permissible deviation of $10 \%$, in all other cases it is necessary to find out the reasons for the failure to fulfill the tasks and take measures to eliminate them.

In addition, tasks must be fulfilled on time. According to the efficiency criterion of the PMU, there can be an indicator of the efficiency of the fulfillment of PMU tasks, which reflects how timely the tasks are performed and is calculated as:

$$
\text { Trz=tvzf/tvzp }
$$

where tvzf is the actual duration of the assigned tasks; tvzp is the planned time to complete the assigned tasks.

The level of professionalism of the PMU will be determined by the share of employees who have an appropriate level of professional training in performing work on personnel management, confirmed by relevant documents (diplomas, certificates, etc.) in the total number of PMU employees This indicator will be calculated as (IO1):

$$
\mathrm{IO} 1=\mathrm{Nf} / \mathrm{Nzag}
$$

where $\mathrm{Nf}$ is the number of employees who have an appropriate level of professional training in performing work on personnel management, which is confirmed by the relevant documents (diplomas, certificates, etc.); Nzag is the total number of PMU employees. 
We consider it expedient to calculate organizational efficiency not only for the entire personnel management system, according to the indicators given above, but also for the position of evaluating the work of each of the 12 subsystems. Accordingly, this will be the structural direction of organizational effectiveness. Let us consider what indicators can be used to evaluate their work.

The personnel planning subsystem should ensure the formation of plans of work with personnel and their implementation to the maximum extent. Accordingly, the work of this subsystem can be assessed by the level of fulfillment of planned targets for work with personnel (EP1):

$$
\text { Ep1=Npl_v/Npl_zag }
$$

where Npl_v - the number of completed plans for working with personnel; Npl_zag - the total number of plans for working with personnel.

The work of the subsystem will be considered effective if the value of this indicator is close to $0.8-1$.

The next subsystem - staffing for ensuring entrepreneurial activity is created at the enterprise with the aim to provide high-quality staff for ensuring production and economic activities. We propose to evaluate the work of this subsystem by analyzing the level of staffing (EP2):

$$
\mathrm{EP} 2=\mathrm{Nk} / \mathrm{Nk} \_\mathrm{zag}
$$

where $\mathrm{Nk}$ is the actual number of employees at the enterprise; Nk_zag - the general need for personnel in the whole enterprise.

If this indicator is close to 1 , then the enterprise does not need new personnel, and the work of the subsystem will be considered positive. The efficiency limitation may be the indicators of staff turnover and the professional and qualification level of involved employees. That is, if the company experiences a high level of staff turnover or the hired workers do not meet the requirements to fulfill the assigned tasks, then the work in the field of staffing should be reviewed and measures should be taken for more stringent selection of workers, as well as measures to dismiss workers on the basis of resignation.

The subsystem of rotation and personnel reserve in personnel management is one of the tools that allows solving the problem of personnel shortage. In modern conditions, when workers have the opportunity to freely access foreign employment markets, domestic enterprises face a problem of keeping highly qualified specialists at the enterprise. Accordingly, in order not to disrupt the process of activity, it is important to ensure the establishment of positions at the enterprise for which a staff drain may occur and to train employees who can take vacant positions. Thus, it is much easier for an enterprise to create a reserve team from existing specialists than to find a suitable employee using various recruiting tools. Consequently, the personnel reserve subsystem will work effectively if the following types of work are carried out and evaluated at the enterprise:

- assessment of the staffing for the appearance of posts that will require staff replacement;
- formation of the optimal portfolio of the personnel reserve, which may need to be replaced, in order to avoid suspension of activities;

- formation of a portfolio of reserve workers (assessment and selection of candidates who can take reserve positions);

- staff rotation when a vacant position appears;

- evaluating the work of employees who were in rotation in the process of formation of the personnel reserve.

To assess the effectiveness of the personnel reserve subsystem, it is advisable to calculate the indicator of the effectiveness of reserve replacement of vacant positions (EP3), which will be determined by the level of replacement of positions in the personnel reserve and calculated by the formula:

$$
\mathrm{EP} 3=\mathrm{Nrf} / \mathrm{Nr} \_ \text {zag }
$$

where Nrf is the actual number of employees who can be attracted to take vacant positions and meet the requirements of the position that is currently in the talent pool portfolio; Nr_zag - the planned need for employees who can quickly take vacancies in the talent pool portfolio.

The optimal value of this indicator is between 0.8 and 1 . That is, with a value of 0.8 , the formation of the personnel reserve will be considered $80 \%$ completed. To achieve its $100 \%$ fulfillment, the outstaffing personnel reserve scheme can be applied, when external reserves can be created to take vacant positions with the involvement of outstaffing organizations in the field of personnel management. That is, an enterprise, in the absence of applicants for a position, can turn to third-party organizations that provide personnel recruiting.

The next stage in the analysis of the personnel management unit, after it has completed the planning and recruitment of employees, is the analysis of activities, certification, assessment of personnel, etc.

The main criterion for the effectiveness of this subsystem will be to determine how effectively the results of the work of each individual employee and his contribution to the development of the enterprise are evaluated. This subsystem should provide an assessment of the activities of each employee and his role in achieving the established goals of the enterprise. Based on the results of processing literary sources, we can determine the main tasks that this subsystem should perform:

- assessment of professional and business qualities, knowledge, skills, competencies of an employee, which allows to establish the level of his compliance with the requirements of the position;

- assessment of the results of labor activity (quality of work performed, deadlines, productivity, loss of time, etc.).

It should be noted that there is no generally accepted assessment methodology, therefore, a significant number of tools are used in the practice of domestic enterprises. We consider it advisable to pay attention to the fact that 
enterprises can independently choose the method of assessment. However, the emphasis should be placed on performance indicators, which depend on professional skills and personal qualities and the attitude to the tasks performed by employees. This is what determines the choice of the two aspects of assessment mentioned above. And, therefore, to assess the work of the subsystem, we can apply the indicator of comprehensive assessment of the effectiveness of the work of personnel (EP4), which is calculated as:

$$
\mathrm{EP} 4=\mathrm{Ne} / \mathrm{Np} \_z a g
$$

where $\mathrm{Ne}$ is the number of employees whose work, according to the results of the assessment, is recognized as highly effective; Np_zag is the total number of employees at the enterprise.

According to this indicator, the work of the personnel assessment subsystem should be evaluated in dynamics. That is, if there is an increase in this indicator in the time period, then this will confirm that the company periodically and systematically evaluates personnel, identifies employees who ineffectively perform the assigned tasks for various reasons (a discrepancy between professional and qualification characteristics or common unwillingness of the employee to work for the result). Also, the growth of this indicator will indicate that, based on the assessment results, measures are taken to improve the efficiency of personnel.

In addition to assessing the effectiveness of the work of employees, one of the necessary activities of the personnel management unit is to monitor the movement and state of use of personnel at the enterprise, which consists in the well-timed and operative accounting of personnel activities. It is important to evaluate the work of this subsystem not only for the internal economic needs of the enterprise. It is important to take into account that that any employment relationship is regulated by law. Accordingly, the enterprise must timely keep records of personnel for the needs of state statistical offices, pension funds, departments for social protection of the population, and the state tax administration. At the same time, it is important to take into account the fact that, according to the legislation, the company is responsible for providing false or inaccurate information. This, in turn, determines the need to establish the functional tasks of the personnel accounting subsystem in the following vectors:

- operational accounting of personnel work;

- statistical accounting of personnel work.

Operational accounting is carried out in order to establish the real state of staffing at the enterprise for internal economic needs, and statistical accounting is carried out in order to present reporting personnel information to the relevant authorities.

To assess the work of the personnel accounting subsystem, it is necessary to determine its main tasks, which are:

- the formation and accounting of primary information about personnel activities (this includes the current accounting of data on the labor activity of an employee from the moment he was hired and during employment, in particular, maintaining and checking documents for employment, maintaining personal files, time management etc.);

- keeping records of personnel (the most typical for accounting are data on staffing (number, structure by age, gender, professional skills), staff turnover, wages, working conditions, productivity);

- formation of current information about personnel work;

- formation of periodic reporting information on the state of use of personnel.

The personnel accounting subsystem should provide welltimed and reliable information about the state of personnel to both managers and the relevant state bodies, therefore, we propose to evaluate the efficiency of this subsystem by the indicator of the level of personnel accounting (EP5), which will be calculated:

$$
\text { EP5=Nvok/Nok_zag }
$$

where Nvok - the number of completed work on personnel accounting within the appropriate time frame and without violations; Nok_zag - the number of planned work on personnel records according to the plans of the enterprise, the requirements and requests of managers.

The normative criterion for the effectiveness of the personnel accounting subsystem will be the value of the indicator in the range of $0.8-1$, which will indicate the effectiveness of the work, but the best value is at level 1 , since this will help to avoid situations when personnel registration for state reporting was performed incorrectly. Therefore, the enterprise will not face conflict situations with state authorities, which can lead to various kinds of penalties and fines.

It is possible to ensure the effective work of hired personnel in a variety of ways, both with the help of regulatory documents that will determine performance indicators, and by providing appropriate motivation for the employee to achieve planned results and overfulfilment. Motivation is considered as one of the key tools for influencing work results, therefore, both scientists and practitioners pay considerable attention to its research. From the theoretical standpoint, motivation is considered as a set of tools, incentives, motives that induce the most productive activity of participants in production and economic activities. From the perspective of practitioners, HR managers use motivation in two main forms: material and moral. The question of employee motivation is highly individual, therefore, in order to actually motivate a subordinate qualitatively, it is not enough to have a certain set of material incentives, but it is also important to find an approach to each employee, to understand what motivates him or her to work effectively, and then one can apply appropriate motivating measures. So, the motivation subsystem in the structure of the personnel management unit must constantly ensure the establishment of appropriate forms of incentives for highly productive activities of employees. We propose to assess the effectiveness of the motivation subsystem of the personnel management unit by determining the level of employee satisfaction with the incentive system at the enterprise (EP6), which is calculated as: 


$$
\text { EP6=Np_m/Np_zag }
$$

where Np_m - the number of employees who are fully satisfied with the level of material and moral motivation at the enterprise; Np_zag is the total number of employees at the enterprise.

The criterion value of this indicator must be at least 0.8 , since at each enterprise there is always a certain group of employees who will not be fully satisfied with the motivation system.

One of the necessary aspects of the labor activity is the creation of proper, high-quality and safe working conditions, which corresponds to both the requirements of modern scientific and technological development, when an employee cannot perform the tasks assigned to him, if he does not have the appropriate means and tools for this, as well as this is also stipulated by legislative normative legal acts, according to which the employer must provide proper working conditions. Entrepreneurs report this to the state authorities. To create such conditions, a subsystem for creating proper, high-quality and safe working conditions should be included in the structure of the personnel management unit. The performance of this subsystem (EP7) will be assessed for meeting the requirements for working conditions and will be calculated as:

$$
\text { EP7=Np_o/Np_zag }
$$

where Np_o - the number of employees whose working conditions are optimal for the highly productive activities and comply with legal requirements; $\mathrm{Np} \_$zag is the total number of employees at the enterprise.

The standard of this indicator is its value at level 1 , which will indicate that the enterprise ensures the compliance of working conditions with both legal requirements and the requirements necessary to fulfill the tasks.

Any production and economic activity of domestic business entities in the field of labor relations is regulated by constitutional, legislative and other normative legal acts. Accordingly, in the structure of the personnel management unit, a subsystem must be defined that will carry out activities for the legal support of work with personnel. The main tasks of this subsystem are:

- correct registration of labor relations in accordance with the law;

- monitoring compliance with labor legislation;

- tracking changes in labor legislation and their implementation in the activities of the enterprise;

- providing employees with legal advice on their rights in the field of labor relations;

- legal protection of the rights of employees and employers.

The number and types of tasks that this subsystem must perform may differ from enterprise to enterprise, because the norms of legal regulation of labor activity are different, depending on the type of economic activity, However, we propose to evaluate the efficiency of this subsystem (EP8) by determining the level of fulfillment of the assigned tasks. This indicator is calculated as:

$$
\mathrm{EP} 8=\mathrm{Nz} \_\mathrm{v} / \mathrm{Nz} \_\mathrm{p}
$$

where $\mathrm{Nz}_{-} \mathrm{v}$ - the number of completed tasks in the field of information and legal support and support of personnel management issues; $\mathrm{Nz} \_\mathrm{p}$ - the number of tasks scheduled to be performed in the field of information and legal support and support of personnel management issues.

The normative value of the efficiency of the subsystem of information and legal support is 1 , since its lower value will indicate that the enterprise may not partially fulfill the assigned tasks in the field of legal support, which in turn may lead to a violation of labor legislation and will have negative consequences for the enterprise.

One of the requirements for the development of an enterprise in a changing external environment is its ability to provide activities using the optimal amount of resources with the most productive feedback. As for any production and economic or business processes, all types of resources are used in the work of the personnel management unit, and therefore there is a need for their correct attraction, formation and application. For this, we propose to allocate a subsystem of resource support for work with personnel as part of the personnel management unit. The main tasks of this subsystem is the formation of an optimal set of resources, which ensures the effective work of the personnel management unit, while putting the main emphasis on the following resources:

- labor resources (the personnel management unit must be provided with employees who have experience working with personnel, who have basic competencies in personnel management, certified by the relevant qualification documents);

- financial resources (to ensure work with personnel, the personnel management unit must have funds to carry out all types of activities related to personnel);

- information resources (provide for the possibility of carrying out work by the personnel management unit using specialized information resources and software products);

- material and technical resources to perform work with personnel.

If the enterprise has a sufficient amount of the resources mentioned above, then the task of the personnel management unit can be considered productive and fulfilled. This, in turn, will allow us to calculate the efficiency of the subsystem (EP9) as follows:

$$
\mathrm{EP} 9=\mathrm{Nr} \_\mathrm{f} / \mathrm{Nr} \_\mathrm{p}
$$

where $\mathrm{Nr}$ - $\mathrm{f}$ - the actual amount of resources used in the work of the personnel management unit; $\mathrm{Nr} \_\mathrm{p}$ - the amount of resources required for the effective work of the personnel management unit.

The standard value of this indicator is in the range of $0.8-1$, since a value of 0.8 means that the enterprise has a sufficient level of resource provision to fulfill the assigned tasks. 
To support the activities of personnel and ensure their compliance with the requirements of the external environment at the enterprise, employer needs to ensure professional development of employees. Professional development of personnel is a purposeful and systematic impact on employees through the implementation of vocational training during their employment in the organization in order to achieve high efficiency of production or services provided, increase the competitiveness of personnel in the labor market, ensure that employees perform new and more complex tasks on the basis of the maximum use of their abilities and potentialities. Based on the processing of data on the activities of domestic enterprises, we have established that almost every enterprise is engaged in professional development of personnel. There are various forms of professional development of personnel, from self-training of an employee to education on the basis of various organizations and institutions that provide professional development services that meet the needs of the enterprise.

\section{CONCLUSION}

Thus, we determined the need for the functioning of the subsystem of training and improvement of professional and qualification characteristics within the personnel management unit, which will track the need for professional development and promote it among employees

Note that it is advisable to calculate the indicators of organizational efficiency not only for the already formed personnel management unit, but also at the stage of its structural filling. This means that all the processes that we propose to define for certain subsystems of the personnel management unit in one way or another occur at the enterprise, and therefore, having calculated the level of their implementation, we will be able to establish the feasibility of intensification of the activities of a particular subsystem, the feasibility of allocating it into a separate subsystem or, on the contrary, combining tasks of the subsystem with existing ones.

The social efficiency of the functioning of the personnel management unit will be expressed by the complex of social results obtained by employees, the enterprise itself and the external environment. However, our assessment will be based on the social impact of the enterprise. The assessment will be carried out by establishing the level of satisfaction with the social benefits created as a result of the activities of the personnel management unit, by all persons who ensure the work of the studied enterprise (that is, here we propose to take into account the founders-owners, managers and personnel).

Consequently, the effective activity of the PMU is expressed both in the performance indicators of the unit itself and in the performance of the whole enterprise, since the main task of the PMU is to ensure the effective work of all personnel of the enterprise. The activities of the PMU will be optimal and effective if the enterprise achieves both the goals in the field of work with personnel and the goals of the enterprise itself. Accordingly, we propose to evaluate the effectiveness of the work of the PMU, which ensures the achievement of the goals mentioned above, on the basis of an indicative approach.

\section{References}

[1] Y.-H. Hung, W.W. Winchester, T.L. Smith-Jackson, B.M. Kleiner, K.L. Babski-Reeves, and T.H. Mills, "Identifying fall-protection training needs for residential roofing subcontractors", Applied Ergonomics, 2013, vol. 44(3), pp. 372-380. https://doi.org/10.1016/j.apergo.2012.09.007

[2] D.A. Wilcox, P.W. Dowrick, and K.M. Ward, "Effectiveness of a model for training direct service personnel in rural and remote locations", Journal of Intellectual and Developmental Disability, 2001, vol. 26(4), pp. 311-323. DOI: https://doi.org/10.1080/13668250120087326

[3] M.R. Baumann, C.L. Gohm, and B.L. Bonner, "Phased training for highreliability occupations: Live-fire exercises for civilian firefighters", Human Factors, 2011, vol. 53(5), pp. 548-557. DOI: https://doi.org/10.1177/0018720811418224

[4] S. Krugilin, "Silvicultural growth models of the formation of Quercus Robur in the black earth zone conditions of the steppe of the South of Russia", World Ecology Journal, 2018, vol. 8(3), pp. 23-45. DOI: https://doi.org/https://doi.org/10.25726/NM.2019.49.29.002

[5] J. Smith, "Assistive personnel: Titles, settings, and training", JONA's Healthcare Law, Ethics, and Regulation, 2004, vol. 6(4), pp. 92-95. DOI: https://doi.org/10.1097/00128488-200410000-00005

[6] A.E. Dupler, and N.L. Crogan, "Comparing needed training with topics of interest among assisted-living providers", Journal for Nurses in Staff Development, 2004, vol. 20(1), pp. 38-41. DOI: https://doi.org/10.1097/00124645-200401000-00007

[7] J.A. Cannon-Bowers, S.I. Tannenbaum, E. Salas, and S.A. Converse, "Toward an integration of training theory and technique", Human Factors, 1991, vol. 33(3), pp. 281-292. DOI: https://doi.org/10.1177/001872089103300304

[8] Y. Yamani, S. Samuel, M.A. Knodler, and D.L. Fisher, "Evaluation of the effectiveness of a multi-skill program for training younger drivers on higher cognitive skills", Applied Ergonomics, 2016, vol. 52, pp. 135141.DOI: https://doi.org/10.1016/j.apergo.2015.07.005

[9] A.M. Hughes, S. Zajac, A.L. Woods, and E. Salas, "The Role of Work Environment in Training Sustainment: A Meta-Analysis", Human Factors, 2020, vol. 62(1), pp. 166-183. DOI: https://doi.org/10.1177/0018720819845988

[10] Y.-H. Huang, S.K. Verma, W.-R. Chang, T.K. Courtney, D.A Lombardi, M.J. Brennan, and M.J. Perry, "Management commitment to safety vs. employee perceived safety training and association with future injury", Accident Analysis and Prevention, 2012, vol. 47, pp. 94-101. DOI: https://doi.org/10.1016/j.aap.2011.12.001

[11] G.W. Polley Jr., L.W. McAllister, T.W. Olson, and K.P. Wilson, "Mental health training for county welfare social work personnel: An exercise in education and community organization", Community Mental $\begin{array}{lllll}\text { Health Journal, 1971, vol. 7(1), pp. 29-38. } & \end{array}$ https://doi.org/10.1007/BF01434730

[12] J.C. Gorman, N.J. Cooke and P.G. Amazeen, "Training adaptive teams", Human Factors, 2010, vol. 52(2), pp. 295-307. DOI: https://doi.org/10.1177/0018720810371689

[13] D. Walter, "Competency-based on-the-job training for aviation maintenance and inspection - A human factors approach", International Journal of Industrial Ergonomics, 2020, vol. 26(2), pp. 249-259. DOI: https://doi.org/10.1016/S0169-8141(99)00069-4

[14] Y. Hu, B. Jiang, H. Kim, A.T. Schroen, P.W. Smith, and S.K Rasmussen, "Vessel Ligation Fundamentals: A Comparison of Technical Evaluations by Crowdsourced Nonclinical Personnel and Surgical Faculty”, Journal of Surgical Education, 2018, vol. 75(3), pp. 664-670. DOI: https://doi.org/10.1016/j.jsurg.2017.09.030

[15] R.S. Shim, and M.T. Compton, "Pilot testing and preliminary evaluation of a suicide prevention education program for emergency department personnel", Community Mental Health Journal, 2010, vol. 46(6), pp. 585-590. DOI: https://doi.org/10.1007/s10597-009-9241-4

[16] M. Levy, R.W. Koch, and M.B. Royne, "Self-reported training needs of emergency responders in disasters requiring military interface", Journal of Emergency Management, 2013, vol. 11(2), pp. 143-150. DOI: https://doi.org/10.5055/jem.2013.0133

[17] T.L. Hall, and R.L. Meile, "Training developing-world personnel in family planning and population: accomplishments and patterns", Studies in Family Planning, 1980, vol. 11(5), pp. 167-177. DOI https://doi.org/10.2307/1965759 
[18] M.S. Wetherill, M.B. Williams, K.C. White, J. Li, J.I. Vidrine, and D.J. Vidrine, "Food pantries as partners in population health: Assessing organizational and personnel readiness for delivering nutrition-focused charitable food assistance", Journal of Hunger and Environmental Nutrition, 2019, vol. 14(1-2), pp. 50-69. DOI: https://doi.org/10.1080/19320248.2018.1512931
[19] D.H. Harris, "The Impact of Microelectronics on the Utilization and Training of Maintenance Personnel", Human Factors: The Journal of Human Factors and Ergonomics Society, 1967, vol. 9(2), 161-174. https://doi.org/10.1177/001872086700900208 